\title{
Hospital Mortality After Major Amputation of the Lower Limbs for Critical Ischemia
}

\author{
José Maria Pereira de Godoy ${ }^{*}, 1$, Janalice Vasconcelos Ribeiro ${ }^{2}$ and Lívia Andrioli Caracanhas ${ }^{2}$ \\ ${ }^{1}$ Livre Docente of the Cardiology and Cardiovascular Surgery Department of the Medical School in São José do Rio \\ Preto (FAMERP), Brazil \\ ${ }^{2}$ Medical School in São José do Rio Preto (FAMERP), Brazil
}

\begin{abstract}
The prevalence of major amputations of lower limbs increases as the population ages. The aim of the current study was to evaluate hospital death in cases of major amputations for critical limb ischemia in a teaching hospital.

Hospital mortality during the peri-operative period was evaluated in 231 major amputations of legs due to critical limb ischemia between January 2005 and 2007. Thirty-six (15.6\%) deaths occurred in this period, 14 women and 22 men (ages between 47 and 86). Of these patients, $13(5.6 \%)$ died during the first hospitalization and $23(9.9 \%)$ during rehospitalizations within the first month.

High death rates were observed in the peri-operative period of major amputations of the lower limbs due to critical limb ischemia.
\end{abstract}

Keywords: Amputation, lower limbs, critical limb ischemia, mortality.

\section{INTRODUCTION}

Approximately $10 \%$ of over 55 -year-olds have asymptomatic peripheral atherosclerotic disease, $5 \%$ have intermittent claudication and $1 \%$ have critical ischemia of the leg (pain at rest or gangrene) [1]. The most important risk factors for the development of critical ischemia of the legs are diabetes, smoking, arterial hypertension, lipid alterations, obesity and low blood pressure in the ankles [1-3]. Without therapy using medications or interventions, around $40 \%$ of these individuals loose their legs in less than 6 months and $20 \%$ die [2].

One study evaluated 2 random perspective trials comparing bypass surgery and angioplasty and found no significant difference in the amputation rates between the surgery and infrainguinal angioplasty groups; however these procedures were employed in only $15 \%$ of the patients with severe ischemia [3].

Of 150,000 amputations annually in the United States of America, peri-operative death occurred in $5 \%$ to $10 \%$ of the cases in which amputation was below the knee, increasing to $50 \%$ for amputations above the knee due to comorbidities [3]. Another study reported a peri-operative mortality rate of $15.7 \%$ [4]. A study in our service reported a mortality rate of $44 \%$ within the first year after major amputations of the legs, $50 \%$ within 2 years and $72 \%$ within 6 years [5]. As well as the high mortality rate, the quality of life of patients deteriorates.

The aim of the current study was to evaluate hospital death in cases of major amputations for critical limb ischemia in a teaching hospital.

*Address correspondence to this author at the Rua Floriano Peixoto, 2950, São Jose do Rio Preto-SP-Brazil, Zipe Code: 15020-010, Brazil; Tel/Fax: 55 17 32326362; E-mail: godoyjmp@riopreto.com.br

\section{METHODS}

Hospital mortality during the peri-operative period was evaluated in 231 major amputations of legs due to critical limb ischemia between January 2005 and 2007 in Hospital de Base of the Medicine School of Sao Jose do Rio Preto (FAMERP). Patients with critical ischemia and necrosis of the lower limbs submitted to amputation above and below the knee were included in this study. The criterion for inclusion in this group was measuring the ankle-brachial pressure index $(\mathrm{ABI})<0.6$. Minor amputations of the foot or toes and amputations due to trauma were not included.

The study was approved by the Research Ethics Committee of FAMERP. Were evaluated the prevalence of events.

\section{RESULTS}

In this period, 36 (15.6\%) deaths occurred; 14 women and 22 men (age ranging between 46 and 86). Of these deaths, 13 (5.6\%) died during the first hospitalization, 1 during $24 \mathrm{~h}$ and 12 during the first week, and 23 (9.9\%) during re-hospitalizations within the first month.

\section{DISCUSSION}

The current study shows a high peri-operative mortality rate for major amputations of the lower limbs due to critical ischemia $[3,4]$. One aspect that highlights the severity of the disease is the internationally published data on mortality rates that report deaths in between $72 \%$ and $92 \%$ of the cases within the first 6 to 8 years of follow up [5,7]. The deterioration of the quality of life after amputation is a second negative factor [6].

These patients require greater postoperative care with respect to pain, edema, mobility of limbs, prevention of contractures and psychological support. Thus, the involvement of an interdisciplinary team is recommended in these cases 
including physiotherapy, occupational therapy, psychology, the supply of prosthesis and social services [8].

The decision to operate or not in critical limb ischemia cases should contemplate revascularization and when the functional capacity of the limb is not restored, primary amputations should be considered [9].

In the current study the patients were treated in a tertiary hospital where referred cases require greater care. The mortality rate during the initial period of hospitalization was $5.6 \%$ which, within 1 month, increased to $15.6 \%$. Another study by the same authors identified a mortality rate of $44 \%$ within 1 year of amputation and 50\% in the first 2 years [5]. Thus, the mortality rate remains high during the first year after amputation. The limitations of this study include that it could not evaluate the factors (e.g. infection, diabetes) [10] involved with each amputation and their possible relationship with mortality. However, we need to alert patients as to the high mortality in this population.

Prevention of peripheral artery insufficiency is of fundamental importance to improve the life expectancy of this population as well as with coronary heart disease.

\section{CONCLUSIONS}

High death rates were observed in the peri-operative period after major amputations of the lower limbs due to critical limb ischemia.

\section{REFERENCES}

[1] Halperin JL. Evaluation of patients with peripheral vascular disease. Thromb Res 2002; 106: V303-11.

[2] Shigematsu H. Epidemiology from the Trans Atlantic Inter-Society Consensus Group Guidelines II. Nippon Geka Gakkai Zasshi 2007; 108: 171-5.

[3] Eskelinen E, Lepäntalo M. Role of infrainguinal angioplasty in the treatment of critical limb ischaemia. Scand J Surg 2007; 96: 11-6.

[4] Sichel L, Chiavetta A, Soma PF, et al. Critical ischemia of the diabetic patient. Minerva Chir 2001; 56: 265-71.

[5] de Godoy JMP, Batigalia F, Trávolo AR, Godoy MF, Monteiro EH. Lower-extremity amputation: a 6-year follow-up study in Brazil. J Orthop Surg (Hong Kong) 2005; 13: 164-6

[6] de Godoy JMP, Braile DM, Buzatto SHG, Longo O, Fontes OA. Quality of life after amputation. Psychol Health Med 2002; 4(7): 397-400.

[7] Hermodsson Y, Ekdahl C, Persson BM. Outcome after trans-tibial amputation for vascular disease: a follow-up after eight years Scand J Caring Sci 1998; 12: 73-80.

[8] Pasquina PF, Bryant PR, Huang ME, et al. Limb deficiency and prosthetic management: Focused review. Advances in amputee care. Arch Phys Med Rehabil 2006; 87: S34-43.

[9] Sottiurai V, White JV. Extensive revascularization or primary amputation: which patients with critical limb ischemia should not be revascularized? Semin Vasc Surg 2007; 20: 68-72.

[10] de Godoy JM, Ribeiro JV, Caracanhas LA. Mortality and diabetes mellitus in amputations of the lower limbs for gas gangrene: a case report. Int J Low Extrem Wounds 2008 [Epub ahead of print]. 